\title{
The Talents as the Most Valuable Intangible Assets of the Company
}

\author{
Andrzej Janowski \\ WSKM Konin, Konin, Poland
}

\begin{abstract}
The increase in the activities aimed at improving the material status of populations and crystallizing the concept of development programs was a derivative of the success of socialist bloc economies, including in particular high growth rates in the initial period, which radically reflected global socio-economic conditions. Also, excellent results were obtained in the ideological sphere, and additionally, the competition with Western capitalist economic model was declared - the end of the last century was a period of initiation of the process of socio-economic transformation in many Central Eastern European countries. One of the precursors of the changes was Poland. However, today, this society has lost the title of a leader in the transition process. One of the phenomena contributing to the deterioration of image is a continual lack of a clear and recognised system of human resource management (HRM), including in particular the model forms of talent management and knowledge of the determinants of destruction of talents. This paper contributes to filling the gaps described in the research activities in the field of talent management.
\end{abstract}

Keywords: assets, effectiveness, human resource management (HRM), organization, talents

Most of the terms associated with the definitions of talent, currently used in the science of human resources management (HRM), stress the fact that its presence is associated with the fulfillment of capacities, knowledge, and positive attitudes manifested in a developed internal motivation. They, combined with a historical dimension of the concept of talent, allow to suggest that talent is associated with the highest balanced values: knowledge, skills, and attitudes to work and learning, or the highest level of competence components (Balewski \& Janowski, 2008).

\section{Competency and Talent Management}

As there is a relationship between the notion of talent and the term of competence, "talent management" can be understood as the management of highest and balanced levels of attitudes, skills, and knowledge. It is also authorized to assume that talent management means taking measures to optimize the trajectory of talent growth in order to implement the plans of the company. Achievement of the best results of actions, as in the case of competence management, ensures their management in accordance with the cycle of organisation and presentation of the company as a system, open for the activities related to the entry, transfer, or exit of talents to the organisation (Listwan, 2005). However, the difficulty associated with such a process is enhanced by several factors. Among them, there is the need for the elimination of permanent belief about harmful conduct of

Corresponding author: Andrzej Janowski, Ph.D., Headmaster of Banking and Insurance Department, WSKM Konin, Konin, Poland; research field: HRM effectiveness. E-mail: andrzej.j@poczta.fm. 
evaluation and ranking to strengthen the position of all those, who achieve the maximum level of specialization by optimizing the components of competence. In addition, another proposed factor is to counteract the "spoilage of talents", i.e., replacement of talented individuals with the employees with a low or medium and balanced levels of competencies, as part of implementation of the goals of the organisation, or to conduct such activities, which result in a reduction of the level of the employees' competencies or introdution of disturbances in the balanced and the highest level of their skills, knowledge, and attitudes (Balewski \& Janowski, 2011). The primary guarantor of the quality of these activities is empirical verification of the determinants of this phenomenon.

\section{Damaged Talents: The Model and Its Empirical Verification}

Temporary performance of personal functions, in the enterprises based in Poland, consisting mostly in the implementation of foreign concept (Purgał-Popiela, 2003), is subject to continuous and specific family influences. Among the factors affecting HRM in Poland are: strong political position of political parties and trade unions, acting as the tribunes of a pauperised part of the society and perception of the state as a universal protector and provider, resulting from intergenerational transmission of values. In the presence of chaos of roles and objectives: states and organizations operating in the market and the people cooperating with them, it is hard to discern the areas of their mutual and balanced impact. This difficulty is further heightened by the marginalization of overall attempts to enclose the phenomena, taking place on the market, including the internal labor market (internal market is composed of the companies, institutions, and non-profit organizations within which the market functions are implemented using specific functional principles).

Therefore, the primary action in the research aimed at identifying the factors determining the "talents' destruction" is to carry out empirical assessment of the scale of the impact on this phenomenon exerted by each of the three participants in market exchange processes.

The analysis of the data obtained as a result of conducted research (The study was conducted in the years 2007-2008 among the personnel of the enterprises of the Southern and Eastern Wielkopolska. The following sectors were represented in the study: industry, construction, trade, banking services, transport, communications, education and upbringing, as well as utilities. Altogether, the study conducted variably included: 82 persons referred to as talented, 1,806 as associates of talents, and 41 as the managers of talents) allows to observe the importance of diversity in the evaluation of the impact of the state on the destructing of talents through inefficient elimination of unemployment and elements of education policy. The highest values in the state's influence on the destruction of a conglomerate of capabilities, knowledge, and attitudes were indicated by the persons referred to as talented, and the lowest values were indicated by their associates.

Taking into consideration the Cartesian assumption of implicit evidence, the diversity of obtained results of the studies on how the state can destruct talents can be placed in the numerical range, from - 1 to 1 . At the same time, this allows to unambiguously confirm the existence of the phenomenon of the state's influence on the phenomena of destructing of talents.

Another participant in the exchange processes, occurring in the markets subjected to the study whose task is to determine whether and to what extent its performance affects the spoiling of talent, is an organisation, where a talent is realised through professional activities.

The data acquired in the course of research indicate the diverse assessment of the extent of influence of organizations employing talented people on destroying their highest potential abilities, knowledge, and attitudes toward work and learning. 
Differentiation of assessments of the impact of the company/non-profit organizations on the destructing of talents has a different character than the classification of the state's influence on this subject. This is demonstrated first in assigning higher average values $(4+3+2=3$ average $)$ to the impact of internal labour market on the destruction of the highest balanced level of conglomerate: abilities, knowledge, and attitudes, than to the value of impact of the state on this phenomenon. It is also shown that the lowest value of the impact of internal labour market on the destruction of talents has been observed by the managers of the persons indicated as organisational talents $(+2)$, and not as in the case of research on the influence of the state on the studied phenomenon, their associates $(+3)$.

The third category, subjected to the analysis of the impact on the destructing of talents, was talented people. In the reference books, a source of destruction of outstanding talents (associated with the concept of talent), used in the course of actions for the purpose of completion of the objectives of organization, has been most frequently indicated.

The conducted studies did not exclude this element from the set of the main elements determining the destructing of talents. The participants of the studies, the managers of talents, their associates, and the people characterised by the highest balanced level of ability, knowledge, and attitudes toward work and learning, referred to the fact that talents cause self-destruction.

As opposed to the other two factors covered by the study investigating the degree of impact on the destructing of talents, the assessment of the occurrence of the phenomenon was not significantly different. The participants of the study most often pointed to zero or one (associates of talents: 0 ; managers of talents: 0; talents: 1 ; average value $=0.3$ ).

The value of the most common answers, subjected to further analysis with the support of evidentiary process, did not explicitly allow to point out that such an auto-spoiling was placed in the numerical range from -1 to 1 . This allows to indicate the influence of the persons characterized by the highest balanced level, i.e., ability, knowledge, and attitudes on the destruction of their and other people's attributes of talent.

Research results further show that the spoiling of talents occurs when each of the studied elements interacts individually. In practice, in socio-economic reality, the state and the companies/non-profit organizations as well as talented people constitute a conglomerate arising from culture and its co-creators (see Figure 1).

Therefore, it is appropriate to think that talent can also damage all of the examined elements. However, the scale of the devastating impact is variable and depends on the form of action taken by the state, corporate/non-profit organizations, and talents (people).

$\mathrm{X}$ - state; $\mathrm{Y}$ - person; $\mathrm{Z}$-organization

$$
\mathrm{T}=\Sigma \mathrm{X}+\Sigma \mathrm{Y}+\Sigma \mathrm{Z} \leftrightarrow \Sigma(\mathrm{Xn}, \mathrm{Ym}, \mathrm{Zp})
$$

$\mathrm{x} \rightarrow 1 \ldots \mathrm{n} \mathrm{y} \rightarrow 1 \ldots \mathrm{m} \mathrm{z} \rightarrow 1 \ldots \mathrm{p}$ where: $\mathrm{n}=\{1,2,3\}, \mathrm{m}=\{1,2\}, \mathrm{p}=\{1,2,3,4\}$

Yet, further action is required to define the elements of individual sets, i.e., the identification of forms and values of the characteristics and activities of each killer of talents factor. In practice, this happened on the basis of empirical verification of hypotheses, defined in the context of current analysis and assessment of expert groups, i.e., representatives of the world of politics, business, and education. As a result, it was possible to examine the implications for the destructing of talents in the three sets of activities: state $\{\mathrm{X}$ set $\}$, person $\{\mathrm{Y}$ set $\}$, and company/non-profit organization $\{Z$ set $\}$. 
Initially, the $\mathrm{X}$ set consisted of social and educational policy of the state as well as the level of development of social capital in the region and social stratification. As a result of conducted studies, the set of attributes and actions of the state determining spoiling of talents was reduced to three elements, and social stratification was excluded from the set.

\section{CULTURE}

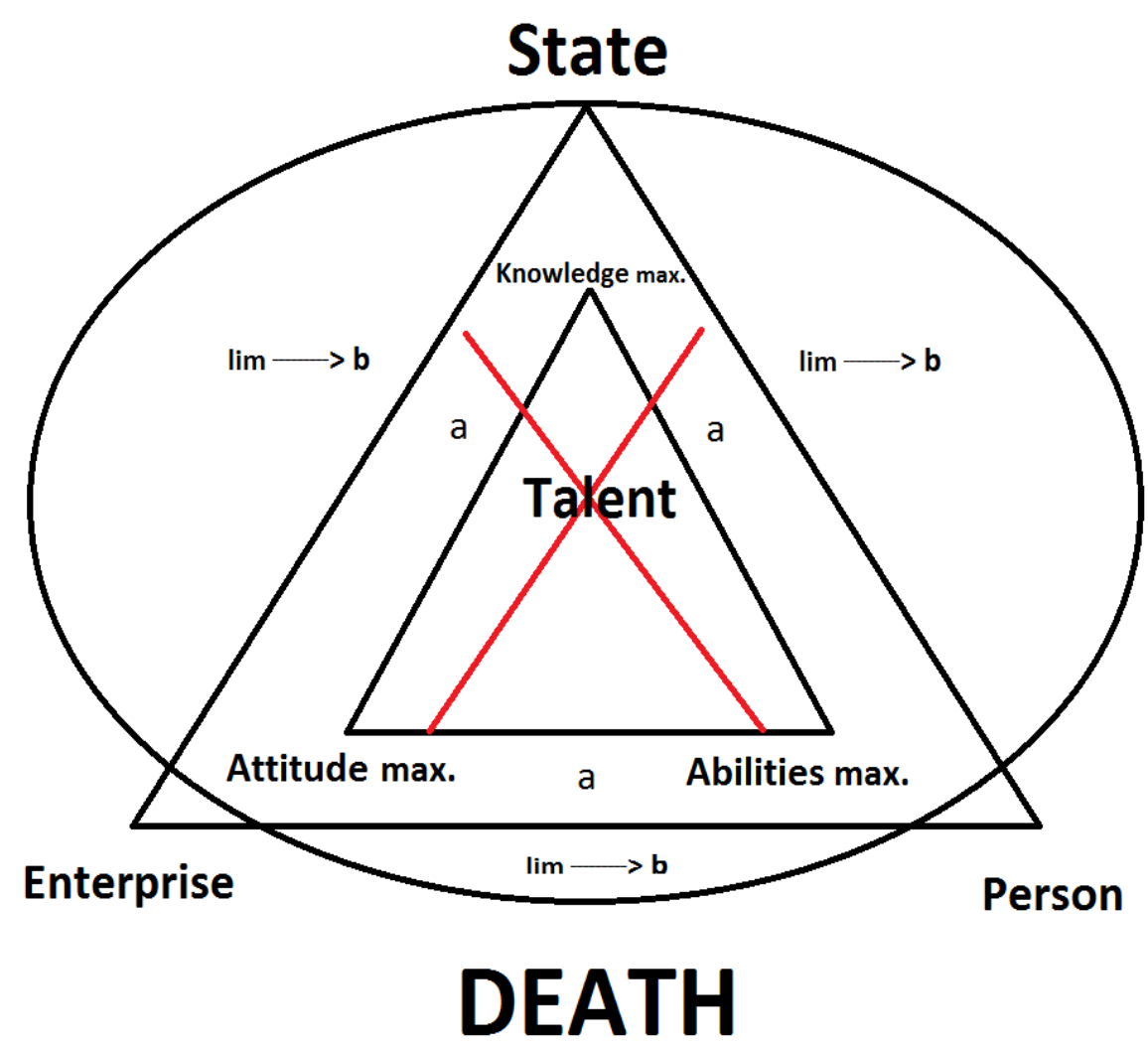

Figure 1. Talent relationship, the factors spoiling talent and culture. Source: the author's own study. Notes. lim $\mathrm{b}$ - perfect boundaries of the state of balance of relations: state, organization, and person; a - state of balance among the components, co-creator, and talent.

The analysis of the answers explaining the degree of impact of stratification given by the participants of the research, i.e., associates of talents, their managers, and the persons characterised by the highest balanced level of ability, knowledge, and attitudes, shows the focus of indicated values in a common point equal to -5.

The opinion expressed by the respondents indicates that "stratification"- natural for society (Sztompka, 2004), contrary to positivist ideas, does not contribute to the destruction of talents through the mechanism of the state. According to the respondents, constitutional solutions applicable in most modern European countries, eliminate stratification and disseminate the ideas of open society, i.e., where individual or group promotion is not only possible within wide limits but also highly expected by the society and state agencies.

Other pre-specified elements of the set, i.e., educational and social policy of the state as well as the level of development of social capital in the region were considered by the participants of the studies as the features and activities of the state, determining the occurrence of talent destruction (see Table 1). 
Table 1

Summary of the Assessments of the Influence of Social and Educational Policy of the State and the Level of Social Capital on the Destructing of Talents

\begin{tabular}{|c|c|c|c|}
\hline \multirow{2}{*}{ Type of study } & Social policy & Educational policy & $\begin{array}{l}\text { Level of social capital } \\
\text { development in the region }\end{array}$ \\
\hline & \multicolumn{3}{|c|}{ The most often indicated value of the factor } \\
\hline Talents & 3 & 4 & 2 \\
\hline Associates & 2 & 4 & 2 \\
\hline Managers of talents & 4 & 4 & 3 \\
\hline Average value of the factor & 3 & 4 & $2,(3)$ \\
\hline
\end{tabular}

Note. Source: the author's own study.

The opinion expressed by the respondents indicates that the state can destroy talents through social and educational policy and the level of social capital present in it (see Table 2).

Table 2

Approximate Values of the Elements of the State's Set, as a Factor Deteriorating a Talent

\begin{tabular}{lll}
\hline$X<0$ & $X>0$ & $X=0$ \\
\hline (1) $\sum(0,0,-1)=-1$ & (1) $\sum(0,0,1)=1$ & (1) $\sum(0,0,0)=0$ \\
(2) $\sum(-1,0,-1)=-2$ & (2) $\sum(-1,1,1)=1$ & \\
(3) $\sum(-1,-1,1)=-1$ & (3) $\sum(1,1,0)=2$ & (2) $\sum(-1,1,0)=0$ \\
(4) $\sum(-1,-1,-1)=-3$ & (4) $\sum(1,1,1)=3$ & \\
\hline
\end{tabular}

Note. Source: the author's own study.

The "talents" will be destroyed by the state in a situation, where the sum of characteristics and activities will be less than zero, with a simultaneous lack of compensation of harmful activity of the state with another factor $[(X, Y, Z)\{(-1,0,-1),(-1,-1,1),(-1,-1,0),(-1,0,0)\}]$, i.e., "destructing of talents" by the state system will not be compensated by the organisation activating talents in professional terms, or by the same persons characterised by the highest balanced level of ability, knowledge, and attitudes (see Table 3).

Table 3

Summary of the Combination of Factors Influencing the Spoiling of Talents

\begin{tabular}{lllllll}
\hline $\mathrm{X}, \mathrm{Y}, \mathrm{Z}$ & 0,0 & 0,1 & $-1,0$ & 1,1 & $-1,1$ & $-1,-1$ \\
\hline 0 & $0,0,0$ & $0,1,0$ & $-1,0,0$ & $1,1,0$ & $-1,1,0$ & $-1,-1,0$ \\
+1 & $0,0,1$ & $0,1,1$ & $-1,0,1$ & $1,1,1$ & $-1,1,1$ & $-1,-1,1$ \\
-1 & $0,0,-1$ & $0,1,-1$ & $-1,0,-1$ & $1,1,-1$ & $-1,1,-1$ & $-1,-1,-1$ \\
\hline
\end{tabular}

Note. Source: the author's own study.

"Spoiling of talents" by the state may also occur when the characteristics and activities constituting the elements of the $\{\mathrm{X}\}$ set have a negative value, that is, if there is ineffective social policy, no action for the development of gifted children and young people is observed, and there is a low level of development of social capital in dynamic terms (see Table 4).

The spoiling of talents caused by the state's destruction of harmony among the highest potential of abilities, knowledge, and attitudes embodied in a person will also occur when the value of each factor will be greater than zero $[(X, Y, Z)=\{(1,1,0),(1,1,-1)\}]$, that is when it is observed simultaneously-beneficial for 
potential abilities, knowledge, and attitudes of the state's actions and one of the remaining participants in the exchange processes.

Table 4

Types of Attributes and Actions of the State, Influencing the $\{X\}$ Value

\begin{tabular}{|l|l|l|}
\hline $\mathrm{X}<0$ & $\mathrm{X}>0$ & $\mathrm{X}=0$ \\
\hline $\mathrm{x} 1=$ ineffective social policy & $\mathrm{x} 1=$ effective social policy & $\begin{array}{l}\mathrm{x} 1=\text { threshold of effectiveness of social } \\
\text { policy } \\
\mathrm{x} 2=\text { no actions taken to support the } \\
\text { development of gifted children and youth } \\
\text { educational activities aimed at developing } \\
\text { talented young people } \\
\mathrm{x} 3=\text { the average level of social capital }\end{array}$ \\
$\begin{array}{l}\mathrm{x} 3=\text { low level of social capital in dynamic } \\
\text { terms }\end{array}$ & $\begin{array}{l}\text { focused on the development of gifted } \\
\text { people } \\
\mathrm{x} 3=\text { high level of social capital in } \\
\text { dynamic terms }\end{array}$ & \\
\hline
\end{tabular}

Note. Source: the author's own study.

The state may also remain in a neutral position with respect to the persons characterized by the highest balanced level of ability, knowledge, and attitudes (see Table 5).

Table 5

Requirements of Neutrality of the State With Respect to the Spoiling of Talents

\begin{tabular}{|l|l|}
\hline $\mathrm{X}=0$ & Requirements \\
\hline $\mathrm{x} 3=0 ; \mathrm{x} 2=0 ; \mathrm{x} 1=0$ & $\begin{array}{l}\text { Average level of social capital; individual non-systematic educational and upbringing activities aimed at } \\
\text { developing gifted children and youth; threshold of the effectiveness of social policy }\end{array}$ \\
\hline $\mathrm{x} 3=1 ; \mathrm{x} 2=0 ; \mathrm{x} 1=-1$ & $\begin{array}{l}\text { High level of social capital in dynamic terms; individual non-systematized educational-upbringing } \\
\text { activities aimed at developing gifted children and youth; ineffective social policy }\end{array}$ \\
\hline $\mathrm{x} 3=-1 ; \mathrm{x} 2=0 ; \mathrm{x} 1=1$ & $\begin{array}{l}\text { Low level of social capital in dynamic terms; individual non-systematized individual educational } \\
\text { activities aimed at developing gifted children and youth; effective social policy }\end{array}$ \\
\hline $\mathrm{x} 3=-1 ; \mathrm{x} 2=1 ; \mathrm{x} 1=0$ & $\begin{array}{l}\text { Low level of social capital in dynamic terms; effective educational policy toward the development of } \\
\text { gifted people; threshold of the effectiveness of social policy } \\
\text { development }\end{array}$ \\
\hline $\mathrm{x} 3=0 ; \mathrm{x} 2=-1 ; \mathrm{x} 1=1$ & $\begin{array}{l}\text { Average level of social capital; lack of measures for the development of gifted children and youth; } \\
\text { effective social policy }\end{array}$ \\
\hline $\mathrm{x} 3=1 ; \mathrm{x} 2=-1 ; \mathrm{x} 1=0$ & $\begin{array}{l}\text { High level of social capital; lack of measures for the development of gifted children and youth; threshold } \\
\text { of the effectiveness of social policy }\end{array}$ \\
\hline
\end{tabular}

Note. Source: the author's own study.

The state will remain in a neutral position $\{\mathrm{X}\}$ with respect to talents if the observed average values of the elements co-creating the $\{X\}$ set are equal to zero, or in the situations where $\{X\}>0$ and $\{X\}<0$ while one of the other sets has opposite values $(X, Y, Z)=\{(0,0,0),(-1,1,0),(1,0,1),(1,-1,0),(1,0,-1)\}]$, i.e., if the features and operations of the state, organisation, and talented individuals are equal to zero, or when the value of the elements making up the set of the state is assessed below zero and one of the other sets has the opposite value, or when the value of characteristics and actions of the state are defined to be above zero, and one of the remaining sets has the opposite value.

The number of remaining items of the set: person- $\{Y\}$ and enterprise/non-profit organisation $-\{Z\}$, verified in the first stage of the study as the killers of talents, did not decrease in the course of further analysis. The persons participating in the study defined as talents, their associates and managers pointed out that the characteristics and activities of the persons having the highest balanced level of ability, knowledge, and attitudes $\{Y\}$ affecting the spoiling of talent should include self-esteem and self-motivation. 
On the other hand, the $\{Z\}$ set is formed by: the type of personnel strategy, the concept of development of organization and its human resources, and the degree of presence of talent management and transparency of staff selection in the organisation.

As in the case of extent and direction of the effect on the spoiling of talents and the elements of the $\{X\}$ set, the factors that co-create the $\{\mathrm{Y}\}$ and $\{\mathrm{Z}\}$ sets can also spoil talents or remain neutral toward them.

The devastating impact of the company/non-profit organizations on talents and auto-killing occurs when the value of the elements of $\{Y\},\{Z\}$ sets is less than zero (see Table 6).

Auto-killing of talents will also take place if the following factors occurring simultaneously are not compensated: impaired self-esteem along with the disappearance of internal motivation $[\{Y\}=(y 1=0 ; y 2=$ $-1)]$ or neurotic condition resulting from distorted self-esteem and exocentric internal motivation $[\{Y\}=(y 1=$ $-1 ; \mathrm{y} 2=0)$ ], or neurotic condition resulting from impaired self-esteem along with the disappearance of internal motivation $[\{Y\}=(y 1=-1 ; \mathrm{y} 2=-1)]$.

In contrast, non-profit business/organisation will spoil talents when the value of $\{Z\}<0$ or $\{Z\}>0$, and at the same time, no phenomenon of compensation by one of the other sets of factors influencing the occurrence of the phenomenon of spoiling of talents will occur $[(X, Y, Z) \neq 0$ when $(X, Y, Z)\{(-1,-1,-1),(1,1,1),(1,0$, $1),(0,1,1)\}]$, i.e., operations of the organisations motivating in professional terms and harmful to the talents can be compensated, either by a talented person alone or by the state (see Table 7).

Table 6

Types of Characteristics and Actions of Talented Individuals Shaping the $\{Y\}$ Value

\begin{tabular}{|l|l|l|}
\hline $\mathrm{Y}<0$ & $\mathrm{Y}>0$ & $\mathrm{Y}=0$ \\
\hline $\begin{array}{l}\mathrm{y} 1=-1 \text { neurotic condition resulting from a } \\
\text { distorted self-assessment } \\
\mathrm{y} 2=-1 \text { lack of inner motivation }\end{array}$ & $\begin{array}{l}\mathrm{y} 1=1 \text { adequate self-esteem } \\
\text { (feeling a sense of duty, fear of pangs of } \\
\text { conscience, sense of honor) }\end{array}$ & $\begin{array}{l}\mathrm{y} 2=0 \text { exocentric internal motivation } \\
\text { feeling a sense of compassion, } \\
\text { unconditional love and conviction of the } \\
\text { rightness of the case) }\end{array}$ \\
\hline
\end{tabular}

Note. Source: the author's own research.

Table 7

Types of Attributes and Operations of the Company/Non-Profit organizations, Influencing the $\{Z\}$ Value

\begin{tabular}{|l|l|l|}
\hline $\mathrm{Z}<0$ & $\mathrm{Z}>0$ & $\mathrm{Z}=0$ \\
\hline $\mathrm{Z} 1=$ linear concept, cumulative & $\mathrm{Z} 1=$ concept of circular growth & $\mathrm{Z}$ = concept of zero growth \\
development & $\mathrm{Z}$ = systemic talent management & $\mathrm{Z} 2$ = competence management \\
$\mathrm{Z} 2=$ lack of talent management & $\mathrm{Z3}=$ "blue ocean" personal strategy \\
$\mathrm{Z3}=$ "red ocean" personal strategy & $\mathrm{Z} 3=$ lack of a clear personal strategy \\
$\mathrm{Z} 4=$ cronyism and nepotism & cronyism & $\begin{array}{l}\mathrm{Z} 4=\text { selection of staff in a tender } \\
\text { competition }\end{array}$ \\
\hline
\end{tabular}

Note. Source: the author's own study.

\section{Conclusions}

When taking into consideration the results of the study, it should be noted that the spoiling of talents by the state, the organisations activating occupationally the talents characterised by the highest balanced level of ability, knowledge, and attitudes, will occur when the value of each factor is equal to zero, or when there is a compensation of one of the sets with the value of another set, so that the total value is equal to zero, or if each factor is equal to one (see Table 8). 
Table 8

Summary of the Requirements for Compensation of the Values of the Factors Eliminating the Occurrence of Spoiling of Talents

\begin{tabular}{ll}
\hline Neutral state & Requirements \\
\hline & When $X=0 ; Y=-n ; Z=+n$ \\
& When $X=0 ; Y=+n ; Z=-n$ \\
& When $X=-n ; Y=0 ; Z=+n$ \\
Then $X=+n ; Y=0 ; Z=-n$ \\
& When $X=+n ; Y=-n ; Z=0$ \\
& When $X=-n ; Y=+n ; Z=0$ \\
\hline
\end{tabular}

Notes. Where $\mathrm{n}=[-3,3]$; Source: the author's own study.

Then, the balance among the highest value of knowledge, skills, and attitudes will not be disturbed.

\section{References}

Balewski, B., \& Janowski, A. (2008). Organizations and talent destruction. In Z. Janowska (Ed.), Dysfunctions and pathologies of human resource management. Lodz, Poland: Lodz University Publishing.

Balewski, B., \& Janowski, A. (2011). Human performance: Competencies, effectiveness and talent management. Torun, Poland: UMK Toruń.

Borkowska, S. (2005). Talent management. Warsaw: IPiSS Publishing.

Janowski, A. (2015). The development of Polish life insurance market in the context of Austrian School—Client's approach. British Journal of Economics, Management \& Trade, 8(2), 132-143.

Listwan, T. (2005). Talent management-Temporary organizations challenges. Warsaw: IPiSS Publishing.

Olekyn, T. (2010). The competency management. Theory and practice. Poland: Wolters Kluwer Publication.

Purgał-Popiela, J. (2003). Human resources management in the context of European integration. Kraków: Academy of Economy Publishing.

Rogoziński, K. (2012). Quality management. Poland: Wolters Kluwer Publication.

Sztompka, P. (2004). The sociology (p. 354). Kraków: Znak Publishing.

Von Mises, L. (2005). The planned chaos. Warsaw: Fijor Publishing.

Von Mises, L. (2007). Human action. A treatise on economics. Warsaw: Mises Institute. 